\title{
Statistical Approaches to Leaving Religion
}

\author{
Isabella Kasselstrand
}

1 Introducing Statistical Approaches to Leaving Religion

Quantitative research has relatively recently become a prominent approach in the social scientific study of religion. While there are a handful of examples of such studies from the first half of the past century, quantitatively oriented research on religion has been a more common occurrence since the 196os (Voas 2007). Predominantly a result of significant technological advancements in the second half of the twentieth century that allow for complex calculations to be carried out instantaneously by a computer, this development follows a similar surge in the application of statistical methods across the social sciences more broadly (Blalock 1989).

Early quantitative researchers on apostasy (for example Caplowitz and Sherrow 1977; Hunsberger 1976; Roof and Hadaway 1977; Wuthnow and Glock 1973) responded to a need for measuring a changing religious landscape - an undertaking that required statistical tools. Since then, quantitative research has continued to thrive. Today, the amount of resources available for scholars interested in studying religious disengagement quantitatively are abundant and constantly growing. Such resources, which are discussed in this chapter, include a wide range of publicly available data sets as well as statistical software programs that have the capacity to perform advanced statistical analysis.

Although statistical methods are increasingly popular in the study of religion, this approach has been criticised for its limited ability to thoroughly capture diverse meanings that exist in the social world (Gergen 1999). This has also been noted specifically in relation to research on religion and nonreligion. Yamane (2000), for example, asserts that highly subjective phenomena, such as religious feelings and experiences, are inherently unquantifiable. Despite this criticism, statistical methods provide important strengths and insights on apostasy that cannot be discerned from the use of qualitative approaches. Along these lines, Voas (2007) maintains that quantitative research provides rigor, clarity, and the ability to distinguish social trends and patterns.

In this chapter, I explore approaches, opportunities, challenges, and limitations of using statistical methods to study the phenomenon of individuals 
leaving religion. In order to showcase the strengths and dilemmas of this approach, methodological literature and theory are discussed and evaluated alongside a presentation of previous empirical quantitative research studies on apostasy. Finally, this chapter concludes with overall suggestions for researchers who are interested in using this methodological approach.

\section{$2 \quad$ Theoretical Perspectives and Turning Points}

Due to the complex and intricate nature of the object of study, each researcher that uses statistical methods has to carefully consider how to conceptualise apostasy. Yet, I also believe that there is considerable value in adopting a definition that has been used in previous literature. Brinkerhoff and Mackie (1993) reason that apostasy involves disengagement from two major dimensions of religion: "belief" and "community." In operationalising these concepts, the authors focus on indicators of "persistence of beliefs" and "denominational selfidentification." More specifically, they compare respondents' answers to the questions on "childhood denominational identification" and "current denominational identification." Additionally, they examine whether the respondents still maintain the religious beliefs that they were raised in. Brinkerhoff and Mackie (1993) suggest that an apostate is a respondent who used to identify with a religion but no longer does so and who no longer holds the beliefs that he or she was socialised into. Operationalising apostasy by comparing adulthood and childhood religiosity corresponds with core theory in apostasy literature, including socialisation theories that explore the salience and persistence of childhood religious socialisation on religious beliefs and belonging in adulthood (Altemeyer and Hunsberger 1997).

In the same fashion, Streib and Klein (2013) define apostasy as "disaffiliation from a religious tradition." They discuss variables from the cross-national, publicly available data from the International Social Survey Program (Table 23.1) that allow for comparing a respondent's current religious affiliation with the one that he or she grew up in. Using a similar definition, Streib et al. (2011) refer to apostasy as "deconversion" and provide a comparative and contextualised account of leaving religion in the United States and Germany using both quantitative and qualitative methodology. Similarly, Schwadel (2010) studies religious disaffiliation in the United States by comparing current and childhood religious affiliation using data from the General Social Survey.

Statistical methods make a wide range of contributions to our theoretical understanding of individuals who leave religion. One of the key debates 
TABLE 23.1 Repeated Cross-Sectional Data on Individuals

\begin{tabular}{|c|c|c|c|}
\hline Data Source $^{a}$ & Years & Countries $^{b}$ & Access \\
\hline $\begin{array}{l}\text { European Social } \\
\text { Survey }\end{array}$ & $2012-2016$ & $\begin{array}{l}36 \text { European } \\
\text { countries }\end{array}$ & $\begin{array}{l}\text { ESS - European } \\
\text { Research } \\
\text { Infrastructure http:// } \\
\text { www } \\
\text {.europeansocialsurvey } \\
\text {.org }\end{array}$ \\
\hline $\begin{array}{l}\text { General Social } \\
\text { Survey }\end{array}$ & $1972-2018$ & United States & $\begin{array}{l}\text { NorC at the University } \\
\text { of Chicago http://gss } \\
\text {.norc.org }\end{array}$ \\
\hline $\begin{array}{l}\text { International Social } \\
\text { Survey Program }\end{array}$ & $1985^{-201} 7^{\mathrm{c}}$ & 45 countries & $\begin{array}{l}\text { GESIS https://www } \\
\text {.gesis.org/issp }\end{array}$ \\
\hline $\begin{array}{l}\text { World Values } \\
\text { Survey }\end{array}$ & $1981-2014$ & 100 countries & $\begin{array}{l}\text { wvs Association http:// } \\
\text { www.worldvaluessurvey } \\
\text {.org/ }\end{array}$ \\
\hline
\end{tabular}

a While this table lists common large-scale data sources, this list is by no means comprehensive. A collection of a larger number of cross-national and country specific data sources can be found through the Association for Religion and Data Archives (http://thearda.com).

b Not all countries participate in all rounds of the data. For a full list of countries by year, visit respective website.

c Extended module on religion available in 1991, 1998, 2008, and 2018 (forthcoming in 2020).

on religious disaffiliation that quantitative researchers engage in is whether changes in religiosity are due to "age effects," meaning that people's levels of religiosity change as they age, "cohort effects," suggesting generational shifts in levels of religiosity, or "period effects," that assume variations in religious beliefs and practices across different historical time periods. This theoretical question is of great relevance to researchers using quantitative methods to study apostasy. Voas (2007) agrees that distinguishing cohort and age effects is a key challenge that quantitative researches should pay attention to. Some examples of such studies include Hamberg's (1991) longitudinal study on Sweden that shows that while older individuals were more religious, all cohorts saw a decline in subjective religiosity between 1955 and 1970. Using data from the General Social Survey, Chaves (1991) maintains that secularising trends of church attendance in the United States are a result of a combination of age, period, and cohort effects. Also using data from the General Social 
Survey, Schwadel's (2011) study showed that religious service attendance and frequency of prayer declined across cohorts, that biblical literalism was associated with both period and cohort declines, and that belief in the afterlife was stable across cohorts. The author argues that the debate surrounding religious disaffiliation is a result of methodological limitations. However, he explains that there are recent developments in the statistical techniques that are available to researchers, suggesting that today's software programs, such as SPss, $\mathrm{R}$, Stata, and SAS, have the ability to distinguish between the three different effects. More specifically, he describes a technique called "intrinsic estimator models" that allow for unbiased estimates of age, period, and cohort effects, a method he utilizes in his own study. This technique is discussed in-depth in Yang et al. (2008). This development highlights a general trend in the use of statistical techniques in the social sciences, namely that there are continuous advancements that allow us to examine intricate trends, patterns, and relationships that we were previously unable to study.

\section{Methodological Perspectives and Turning Points}

An important methodological concern in the study of apostasy is the availability of data that adequately grasp the dynamics of leaving religion. The most common source of secondary data is "cross-sectional" in nature, which means that data have been collected from a particular group of individuals at one point in time. Many large-scale, cross-sectional data sets (see Table 23.1) repeat the implementation of the same (or very similar) surveys at multiple points in time, but with different participants. This type of data is called "repeated crosssectional data." These data sets include a range of variables on various topics of interest to social scientists across different fields of research. For example, they provide information on respondents' opinions on different political and social issues, their demographic characteristics, and perhaps of most relevance for studies on apostasy, their religious affiliation, beliefs, and behaviour.

While repeated cross-sectional data on individuals' current religious beliefs and practices can offer important insights on societal trends of religious change (for example the percentage of respondents who identify with a religion across different years), they are unable to examine changes at the individual level (such as whether a particular person has left the religion that he or she was raised in). Although this can be done through survey questions that ask individuals to recall past religious affiliation, practices, and beliefs, there are also limitations to using data gathered on respondents' memories of their 
childhood. While Brinkerhoff and Mackie (1993: 240) use this approach in their own study on apostasy, they maintain that "the literature is replete with the pitfalls of relying on memory in reporting beliefs and behaviors from the past."

"Panel studies," which consist of data that are collected from the same sample of the same respondents at multiple points in time, are perhaps the most useful type of data for discerning trends of apostasy since they measure the changes in religiosity for each individual over time, without relying on his or her memory or on assumptions that two different samples are comparable. However, collecting this type of data requires extensive resources and long-term commitment. Thus, there are few such data sources available. Nevertheless, there are a number of noteworthy examples of studies on apostasy that are based on panel data. For example, Sherkat and Wilson (1995) analyse religious switching and disaffiliation between senior year of high school and eight years later. They use American data from two waves (1965 and 1973) of the Youth-Parent Socialization Panel Study (Interuniversity Consortium for Political and Social Research) to explore the effects of social ties on religious switching and apostasy, concluding that women, Conservative Protestants, individuals with children, and people with lower levels of education, are less likely to be apostates. They further advocate for panel data as filling important gaps in studying religious dynamics. Using panel data from the first (1994-1995) and the third (2001-2002) waves of the National Longitudinal Study of Adolescent to Adult Health (Add Health), Uecker et al. (2007) examine declines in religious participation, affiliation, and personal importance of religion among American youth who were seventh to twelfth graders in the first wave and 18-25-year-olds in the third wave. One dimension of their study emphasizes behavioural factors, showing that those who engaged in premarital sex, who had consumed marijuana, and who used alcohol experienced the largest decline in religion (see Table 23.2).

Scholars use a variety of descriptive and inferential techniques in the pursuit of studying apostasy. "Descriptive analysis" involves the most basic forms of statistical analysis, whereby researchers examine the distribution of responses within and across relevant variables on religious disengagement. Such analysis involves frequency tables, charts, and summary measures (such as mean, median, mode, range, and standard deviation), as well as basic bivariate tables. Examples of such statistical analysis include Streib's (2012: 6) finding that $11 \%$ of Americans and $14 \%$ of Germans are religious disaffiliates and that Germans are more likely than Americans to cease to believe in God (see Table 23.3); and Caplovitz and Sherrow's (1977) many bivariate tables of apostasy across various demographic variables (such as religion of origin, geographical region, size of home town, parental relations, career intellectuality, and type of college attended). 


\section{Attendance Importance of Disaffiliation} Religion

\section{Premarital Sex}

Had sex before age at marriage 72.8

21.0

$17 \cdot 5$

Did not have sex before

49.6

15.1

14.1

age at marriage

Marijuana Use

Has ever smoked marijuana

Has never smoked marijuana

Alcohol Consumption

Increased alcohol consumption

60.4

16.5

Did not increase alcohol

73.0

21.1

17.2

consumption

All Young Adults

62.0

18.4

16.7

68.6

20.0

17.0

Adapted from Uecker et al. (2007: 1676) with data from Add Health (1994-1995; 2001-2002)

TABLE 23.3 Changes in Belief in God

Which best describes your belief about United States Germany God?

I don't believe in God and never have

I don't believe in God now but I used to I believe in God now, but I didn't used to I believe in God now and I always have

$\begin{array}{rr}4.2 \% & 28.3 \% \\ 5.4 \% & 15.2 \% \\ 7.3 \% & 8.5 \% \\ 83.1 \% & 47.9 \% \\ 100 \% & 100 \%\end{array}$

Adapted from Streib (2012: 6) with data from ISSP (2008).

While the goal of descriptive analysis is to provide an overview of the characteristics of a sample, "inferential statistics" aims to generalize findings from a sample to a larger population. This approach includes some bivariate techniques (for example Pearson's R correlation, ANOvA, t-test, and chi-square) and various multivariate options (such as linear and logistic regression 
techniques). Examples from the empirical literature on apostasy include, for example, Suh and Russell's (2015) multivariate regressions on religious changes using 2006-2010 panel data from the General Social Survey that show that the religiously unaffiliated become more secular over time and score the lowest on every measure of religiosity. Additional examples are Hertel's (1988) regression and ANOVA results that show that workforce participation rates among apostates differ by gender, whereby women who are apostates have the highest levels of participation in the labour force while male apostates have the lowest levels.

The key strength of multivariate compared to bivariate inferential techniques are that they allow for studying the relationship between two variables while controlling for a range of potentially intervening factors. This is a necessary step in order to suggest a causal relationship between two variables. For example, Kasselstrand et al. (2017) use multivariate analysis of data from the World Values Survey to show that, compared to those who are religious, atheists and the nonreligious Americans are significantly less likely to have confidence in social and political institutions, even after controlling for general trust, religious service attendance, age, marital status, education, gender, race, income, and political views.

Both descriptive and inferential statistics can tell us much about apostasy in the modern world. Inferential statistics calculate the probability that the findings from a smaller sample reflect characteristics or relationships in a larger population. Given that we rarely have access to an entire population in social science research, it gives us an opportunity to study the population with a smaller, more easily attainable sample. On the other hand, while descriptive findings are not generalizable to a larger population, such analysis "can be quite revealing, providing insights that would not otherwise be apparent" (Black 1999: 46). More specifically, descriptive findings can offer a broad overview of measures and characteristics of apostasy that are more reader friendly, in particular for an audience that is not well-versed in statistics. With a strong, representative sample, it is also possible to add an inferential component to basic univariate and bivariate statistical tests (such as chi-square to a bivariate table and confidence intervals to sample means). In other words, even researchers without advanced quantitative skills in multivariate inferential statistics can produce findings from survey data that are of crucial value in the field.

\section{$4 \quad$ Critical Reflexions, Evaluations and Predictions}

While there are countless opportunities to further our understanding of apostasy with statistical methods there are also several challenges associated 
with this type of research. One challenge lies in understanding the effects of survey question and response option wording on the overall findings (Davie 2007; Willander 2014; Wuthnow and Glock 1973). Brinkerhoff and Mackie (1993) note that one of the reasons for why studies often report diverse levels of religious disaffiliation is due to differences in how questions are asked in surveys. For example, there are distinct outcomes when comparing a question that asks about religious identification, religious belonging, and religious membership. They also mention that the surveys that are used to collect data are seldom made available to the readers in published literature. Along with this, Bruce (2002) argues that current research on religious decline has methodological deficiencies. More specifically, he argues that some scholars invent latent religiosity by using leading questions, questionable cut-off points in categorising and analyzing data, by wrongfully interpreting largely secular responses as religious, and by failing to adopt a critical approach in relation to the meanings behind people's values and attitudes on religion.

While attention to questionnaire construction is vital when studying religious decline, with various data sets designed to compare trends at a crossnational level, it is also important to note that survey measures on religiosity generally do not consider the diverse conceptual meanings found in different environments. Along these lines, Davie (2007:114) speaks of the necessity to "take into account cultural specificity, historical trajectory, linguistic nuance, and culturally varied motivations." Likewise, while some large-scale data sets (such as the World Values Survey and the International Social Survey Program) provide information on non-Western contexts, a large abundance of accessible survey data are shaped by Western, primarily Christian, conceptions of religiosity (Spickard 2017).

In other words, applying set survey items to multiple contexts broadly overlooks the historical and cultural processes that have shaped the meaning of being religious or secular in a certain context. For example, many secular Europeans, particularly in Scandinavia, identify with the national churches and use them for life cycle ceremonies as a recognition of a cultural heritage despite being nonbelievers in God (Kasselstrand 2015; Zuckerman 2008). This is in line with Hervieu-Léger's (2006: 48) argument that it is possible to "belong without believing" suggesting that one can believe in the social aspect of religion. Likewise, many Europeans "believe without belonging" in that they have rejected organised religion while still holding personal religious beliefs (Davie 2007). Given that apostasy may not necessarily encompass a simultaneous rejection of all dimensions of religion, it is thus important to clearly define what constitutes "leaving a religion," when considering diverse sociocultural contexts. On this note, it is also worth considering whether a person who rejects all 
dimensions of religion, or who has become a self-defined atheist, is necessarily a more salient apostate than an individual who rejects certain dimensions of religion or who has simply become apathetic to religion.

Furthermore, the experiences of leaving a religion are evidently largely different across different cultures and religions. Indeed, the process of "coming out" as atheist or agnostic has stronger normative implications in certain contexts. For example, the role conflict associated with revealing an atheist identity in the United States (Smith 2011) is much more pervasive than in more secular contexts, with widespread religious indifference (Kasselstrand 2016). Thus, one needs to carefully consider such implications when analysing largescale cross-national data sets on religion. Bruce (2002) highlights contextual norms as a challenge in studying religious change using survey methods as core values and expected behaviours of the specific social group may influence how respondents answer survey questions, referring to a study by Hadaway et al. (1993) that showed that Americans tend to exaggerate their religious service attendance.

In other words, it is likely that participants give answers that they think the researcher wants to hear. What this means for the study of apostasy is that we need to interpret individuals' responses in relation to dominant social norms and expectations present at the time and the place that the survey was implemented. This may be particularly challenging in longitudinal studies that are based on panel data. For example, individuals may exaggerate their religious involvement during a time period when secularity was particularly stigmatised, only to alter their response in a later survey, following changing social norms, irrespective of their true levels of religious engagement.

In response to the challenges that are associated with using statistical data described in this chapter, I predict that the future will bring an increasing wealth of mixed methods research on apostasy. The main advantage of a mixed methods approach is that by using both quantitative and qualitative elements in a research project, it is possible to combine the strengths of each method and offset their weaknesses. As statistical data can be used to study general trends and as qualitative research explores in-depth meanings, an integration of the two leads to a more comprehensive understanding that may not be possible if using one method alone (Johnson and Onwuegbuzie 2004). With mixed methods, researchers may therefore be able to use statistical data that may be generalised to larger populations while still incorporating more in-depth explanations for the complex processes of apostasy.

I also foresee a growing number of studies that attempt to predict future levels of secularity on the basis of current and past trends. This can, for example, 
be seen in a recent study from Pew Research Center (2015) where present levels of religious affiliation and population growth patterns are used to predict the size of various religions and the unaffiliated in year 2050. Here, the authors argue that although the religiously unaffiliated population will increase in size, as well as in its share of the population in Europe and North America, its proportion of the global population will decline due to different population growth rates in different regions of the world. Another example of research that uses such a methodology is Stolz et al.'s (2016) prediction of religiosity, spirituality, and secularity in 2030 based on trends in 1950 and 2012. This study, based on Swiss data, foresees a continued decline in established religion and a growth in the secular population. While studies that predict future levels of religiosity rely on the assumption that current and past trends will continue into the future, many of these studies offer robust predictions that are of significant value to our field of study. As such, I agree with Bruce' (2002) argument that as social scientists, we should attempt to measure and map out religious trends, despite any potential challenges in doing so.

Finally, the future of secular studies may see an increase in the use of "big data," which is a term used to describe sets of data that are not subject to sampling and are instead generated on entire populations. Such data include census data, various forms of administrative data (for example membership data from religious organisations) and data on internet behaviour gathered from, for example, search engines. Overall, I believe there is potential to expand our use of big data in studying apostasy and secularisation. An example of using big data on internet behaviour to understand religious decline includes Stephens-Davidowitz' (2015) finding that there has been an increase in google searches about doubting the existence of God, a steep decline in searches for churches, and a limited interest in searching for information about Jesus and the Pope. In fact, he notes that the celebrity Kim Kardashian was subject to 49 million google searches in the first half of this decade, compared to only five million for Jesus Christ and three million for Pope Francis. These data offer valuable, detailed, information that reveal trends of changing interests for the large segment of the world's population that accesses the internet for information.

My first suggestion for how to complete a quantitative study on apostasy involves using secondary data (such as one of the data sets discussed in Table 23.1). 
There is a common misconception that primary data is at all times superior. As a matter of fact, in many circumstances, secondary quantitative data analysis may serve as a stronger and more robust method of research. The perhaps most obvious advantage to secondary data analysis is that it requires considerably less time and resources. Survey construction and implementation that would yield data on apostasy that is generalizable to larger populations is a close to impossible undertaking for a sole researcher with limited resources. Furthermore, secondary data is associated with fewer data collection problems (Kiekolt and Nathan 1985). Many large-scale surveys are administered by organisations employing experts with extensive knowledge on survey construction, sampling techniques, and data collection. These surveys are likewise commonly put through rigorous pre-testing in order to improve the quality of the data. However, it is important to note that when using secondary data sources, a researcher's conceptualisation of apostasy is dictated by the items that are available in the data. For example, most large-scale data sets on religion include indicators on religious affiliation, church attendance, and belief in God, but variables on ritual participation are rare. Thus, more comprehensive measures that thoroughly capture various dimensions of apostasy require collection of original data from surveys designed for this particular purpose.

An important resource for researchers interested in secondary data analysis is the Association of Religion Data Archives (the ARDA) available at http:// www.thearda.com. This database offers public access to a wide range of data sets collected at different levels and across various contexts. What makes the ARDA particularly useful for researchers with limited knowledge in statistics is the fact that they also offer online analysis features on their website, where basic statistical findings for variables of interest can be produced. The data sets are also downloadable and can be analysed with statistical software, such as SPSS, Stata, SAS, and the open source software called R (The R Project for Statistical Computing), available at http://www.r-project.org.

There are countless opportunities to expand our knowledge on individuals who leave religion by using statistical approaches, particularly given the increasing abundance of high quality data for open access and new and improving software tools for this purpose. Being able to understand and conduct such analysis is increasingly becoming a key to researching secularity. Indeed, without access to statistical data our knowledge of secularisation and apostasy would be limited. It is with the use of such data that we have come to learn about key changes in our population, including the recent but sharp drop in religious belonging in the United States (Sherkat 2014), the decline in religious service attendance in Europe (Berger et al. 2008), and the growth in various religious groups and the unaffiliated population around the world (Pew Research 
Center 2015). In summary, statistical methods are both advantageous as well as necessary when studying patterns of apostasy that move beyond individual experiences.

\section{References}

Altemeyer, B., and Hunsberger, B. 1997. Amazing Conversions: Why Some Turn to Faith and Others Abandon Religion. Amherst, NY: Prometheus Books.

Association of Religion Data Archives. n.d. "Data Archive." At http://www.theARDA. com/archive. Accessed 06/10/2017.

Berger, P., Grace D., and Effie F. 2008. Religious America, Secular Europe? Aldershot, England: Ashgate.

Black, T.R. 1999. Doing Quantitative Research in the Social Sciences: An integrated Approach to Research Design, Measurement and Statistics. London:SAGE Publications.

Blalock, H.M. 1989. "The Real and Unrealized Contributions of Quantitative Sociology." American Sociological Review. 54:3, 447-460.

Brinkerhoff, M., and Mackie, M. 1993. "Casting off the Bonds of Organized Religion: A Religious-Careers Approach to the Study of Apostasy." Review of Religious Research. 34:3, 235-258.

Bruce, S. 2002. God is Dead. Oxford, England: Blackwell Publishing.

Caplovitz, D., and Sherrow, F. 1977. The Religious Dropouts: Apostasy among College Graduates. Beverly Hills, CA: Sage Publications.

Chaves, M. 1991. "Family Structure and Protestant Church Attendance: The Sociological Basis of Cohort and Age Effect." Journal for the Scientific Study of Religion. 30:4, 501-514.

Davie, G. 2007. The Sociology of Religion. London: SAGE Publications.

European Social Survey. n.d. "Data and Documentation." At http://www.europeanso cialsurvey.org/data. Accessed 06/10/2017.

General Social Survey. n.d. "Get the Data." At http://gss.norc.org. Accessed 19/07/2019. Gergen, K.J. 1999. An Invitation to Social Constructionism. London: SAGE Publications.

Hadaway, C., Marler, P., and Chavez, M. 1993. “What the Polls Don't Show: A Closer Look at US Church Attendance." American Sociological Review. 58:6, 741-752.

Hamberg, E.M. 1991. "Stability and Change in Religious Beliefs, Practices, and Attitudes." Journal for the Scientific Study of Religion. 30:1, 63-80.

Hertel, B. 1988. "Gender, Religious Identity and Work Force Participation." Journal for the Scientific Study of Religion. 27:4, 574-592.

Hervieu-Léger, D. 2006. "The Role of Religion in Establishing Social Cohesion." In K. Michalski, ed., Religion in the New Europe. Budapest, Hungary: Central European University Press, $45^{-6} 3$. 
Hunsberger, B. 1976. "Background Religious Denomination, Parental Emphasis, and the Religious Orientation of University Students." Journal for the Scientific Study of Religion. 15:3, 251-255.

Interuniversity Consortium for Political and Social Research. n.d. "Youth-Parent Socialization Panel Study." At http://www.icpsr.umich.edu/icpsrweb/ICPSR/studies/4037. Accessed 06/10/2017.

International Social Survey Program Research Group. n.d. "Archive and Data." At http://www.issp.org. Accessed 19/07/2019.

Johnson, B., and Onwuegbuzie, A. 2004. "Mixed Methods Research: A Research Paradigm Whose Time Has Come." Educational Researcher. 33:7, 14-26.

Kasselstrand, I. 2015. "Nonbelievers in the Church: A Study of Cultural Religion in Sweden." Sociology of Religion. 76:3, 275-294.

Kasselstrand, I. 2016. "Lived Secularity: Atheism, Indifference, and the Social Significance of Religion." In P. Zuckerman, ed., Religion: Beyond Religion. New York: MacMillan Publishing, 37-52.

Kasselstrand, I., Couse, T., and Sanchez, S. 2017. "Institutional Confidence in the United States: Attitudes of Secular Americans." Secularism \& Nonreligion. 6:6, 1-11.

Kiecolt, J., and Nathan, L. 1985. Secondary Analysis of Survey Data. London: SAGE Publications.

National Longitudinal Study of Adolescent to Adult Health. n.d. "Add Health." At http://www.cpc.unc.edu/projects/addhealth. Accessed o6/10/2017.

Pew Research Center. 2015. "The Future of World Religions: Population Growth Projections, 2010-2050." At http://www.pewforum.org/2015/04/02/religious-projections -2010-2050. Accessed 05/11/2017.

R Project for Statistical Computing. n.d. "Getting Started." At http://www.r-project.org. Accessed 06/10/2017.

Roof, W.C., and Hadaway, C. 1977. "Shifts in Religious Preference: The Mid-Seventies." Journal for the Scientific Study of Religion. 16:4, 409-412.

Schwadel, P. 2010. "Period and Cohort Effects on Religious Nonaffiliation and Religious Disaffiliation: A Research Note" Journal for the Scientific Study of Religion. 49:2, 311-319.

Schwadel, P. 2011. "Age, Period, and Cohort Effects on Religious Activities and Beliefs." Social Science Research. 40:1, 181-192.

Sherkat, D., and Wilson J. 1995. "Preferences, Constraints, and Choices in Religious Markets: An Examination of Religious Switching and Apostasy." Social Forces. 73:3, 993-1026.

Sherkat, D. 2014. Changing Faith: The Dynamics and Consequences of Americans'Shifting Religious Identities. New York: New York University Press.

Smith, J.. 2011. "Becoming an Atheist in America: Constructing Identity and Meaning from the Rejection of Theism." Sociology of Religion. 72:2, 215-237. 
Spickard, J. 2017. Alternative Sociologies of Religion: Through Non-Western Eyes. New York: New York University Press.

Stephens-Davidowitz, S. 2015. "Googling for God." At https://www.nytimes.com /2015/og/20/opinion/sunday/seth-stephens-davidowitz-googling-for-god.html? _r=0. Accessed 04/11/2017.

Streib, H. 2012. "Deconversion." In L. Rambo and C. Farhadian, eds., The Oxford Handbook on Religious Conversion. Oxford, England: Oxford University Press, 271-296.

Streib, H., Silver, C.F., Csöff, R.M., Keller, B., and Hood, R.W. 2011. Deconversion: Qualitative and Quantitative Results from Cross-Cultural Research in Germany and the United States of America (Vol. 5). Göttingen, Germany: Vandenhoeck and Ruprecht.

Streib, H., and Klein, C. 2013. "Atheists, Agnostics, and Apostates." In K. Pargament, J. Excline, and J. Jones, eds., APA Handbook of Psychology, Religion, and Spirituality. Washington D.C.: American Psychological Association, 713-728.

Suh, D., and Russell, R. 2015. "Non-Affiliation, Non-Denominationalism, Religious Switching, and Denominational Switching: Longitudinal Analysis of the Effects on Religiosity." Review of Religious Research. 57:1, 25-41.

Uecker, J., Regnerus, M., and Vaaler, M. 2007. "Losing My Religion: The Social Sources of Religious Decline in Early Adulthood." Social Forces. 85:4, 1667-1692.

Voas, D. 2007. "Surveys of Behaviour, Beliefs, and Affiliation: Micro-Quantitative." In J. Beckford and J. Demerath, eds., The SAGE Handbook of the Sociology of Religion, 144-166.

Willander, E. 2014. What Counts as Religion in Sociology? The Problem of Religiosity in Sociological Methodology. PhD. Uppsala Universitet, Sweden.

World Values Survey Association. n.d. “Data \& Documentation.” At http://www.world valuessurvey.org. Accessed o6/10/2017.

Wuthnow, R., and Glock, C. 1973. "Religious Loyalty, Defection, and Experimentation among College Youth." Journal for the Scientific Study of Religion. 12:2, 157-180.

Yamane, D. 2000. "Narrative and Religious Experience." Sociology of Religion. 61:2, 171-189.

Yang, Y., Schulhofer-Wohl, S., Fu, W.J., and Land, K.C. 2008. "The Intrinsic Estimator for Age-Period-Cohort Analyses: What It is and How to Use It." American Journal of Sociology. 113:6, 1697-1736.

Zuckerman, P. 2008. Society Without God. New York, NY: New York University Press. 